\title{
Pharmacokinetics and bioavailability study of two ondansetron oral soluble film formulations in fasting healthy male Chinese volunteers
}

This article was published in the following Dove Press journal:

Drug Design, Development and Therapy

12 August 2015

Number of times this article has been viewed

\author{
Yubing Zhu' \\ Qian Zhang' \\ Jianjun Zou ${ }^{2}$ \\ Meng Wan' \\ Zheng Zhao' \\ Junrong Zhu' \\ 'Department of Pharmacy, \\ ${ }^{2}$ Laboratory of Clinical Pharmacology, \\ Nanjing First Hospital, Nanjing \\ Medical University, Nanjing, Jiangsu, \\ People's Republic of China
}

Background: Ondansetron oral soluble film is designed to be applied on top of the tongue without requiring water to aid dissolution or swallowing, which is especially fitting for nausea and vomiting patients.

Purpose: This study was conducted to compare the bioavailability of two $8 \mathrm{mg}$ ondansetron oral soluble film formulations.

Patients and methods: This randomized, open-label, two-period crossover study was performed under fasting conditions. A total of ten eligible subjects were randomly assigned at a 1:1 ratio to receive a single $8 \mathrm{mg}$ dose of the test and reference ondansetron oral soluble film formulations, followed by a 1 -week washout period and administration of the alternate formulation. The concentrations of ondansetron were assayed using an liquid chromatographmass spectrometer/mass spectrometer (LC-MS/MS) method. For analysis of pharmacokinetic properties, including the peak concentration of $T_{\max }\left(C_{\max }\right)$, AUC from time 0 (baseline) to $t$ hours $\left(\mathrm{AUC}_{0-t}\right)$, and $\mathrm{AUC}$ from baseline to infinity $\left(\mathrm{AUC}_{0-\infty}\right)$, blood samples were obtained at intervals over the 24-hour period after studying drug administration. Tolerability was assessed by monitoring vital signs and laboratory tests (hematology, blood biochemistry, hepatic function, and urinalysis) and by questioning subjects about adverse events.

Results: The mean (standard derivation [SD]) relative bioavailability was 96.5 (23.7\%). The $90 \%$ confidence intervals (CIs) for the log-transformed ratios of $C_{\max }$ and $\mathrm{AUC}_{0-t}$ were $84.71 \%$ $103.28 \%$ and $91.38 \%-108.60 \%$, respectively $(P>0.05)$. Similar results were found for the data without log-transformation. No statistically significant differences were found based on analysis of variance. No significant adverse events occurred or were reported during the study.

Conclusion: As the $90 \%$ CIs based on the differences between the test and reference formulation were within the $80 \%-125 \%$ range for both the $C_{\max }$ and $\mathrm{AUC}_{0-t}$, we concluded that the two formulations were bioequivalent with respect to the rate or the extent of absorption. Both formulations are well tolerated.

Keywords: ondansetron, oral soluble film, LC-MS/MS, bioequivalence

\section{Introduction}

Ondansetron, an available selective serotonin-blocking agent, has been widely used in the treatment of preventing nausea and vomiting caused by cancer chemotherapy, radiation therapy, and surgery. ${ }^{1}$ The approved formulations of ondansetron in the market include intramuscular, intravenous, and oral. ${ }^{2}$ Intramuscular administration of medications can be painful and may be associated with risks for infection, bleeding, and abscess formation. Intravenous administration of medications was often limited with complications such as phlebitis, infiltration, extravasation, and infections. ${ }^{3}$ Although traditional oral formulations can be self-administered, it is not always possible if a
Correspondence: Qian Zhang Nanjing First Hospital, Nanjing Medical University, Nanjing, Jiangsu 210006,

People's Republic of China

Tel +862587726280

$\mathrm{Fax}+862587726287$

Email zhangq0619@163.com 
patient has difficulties in swallowing tablets. Oral soluble film is a novel formulation that can dissolve in seconds and can be swallowed without liquid, which is very fitting for the antiemetic drugs such as ondansetron. ${ }^{4}$

But the pharmacokinetic (PK) properties of oral soluble film ondansetron in Chinese population have not been well reported in the previous studies. Based on the literature search, the PK parameters of oral soluble film ondansetron were reported in the previous study, ${ }^{5}$ but they are not well documented in Chinese population. Considering the effect of racial and genetic differences on drug interactions, the study of the PK properties of oral soluble film ondansetron is necessary.

Therefore, the aim of this study was to investigate the PK properties of ondansetron and the bioequivalence of a test ondansetron soluble film 8 mg (Jiangsu Hengrui Pharmaceutical Co. Ltd., Nanjing, People's Republic of China) and a reference ondansetron soluble film $8 \mathrm{mg}$ (Zuplenz ${ }^{\circledR}$; Galena Biopharma, Inc., Portland, OR, USA) in a healthy Chinese adult male population to obtain regulatory approval for the test formulation. We also established a validated LC-MS/MS method for the determination and quantification of ondansetron in the human plasma.

\section{Materials and methods \\ Subjects and study design}

This open-label, randomized-sequence, single-dose, two-way crossover study involved ten healthy subjects under fasting condition, with 1-week washout period.

Healthy male volunteers aged 18-40 years were eligible for recruitment (body mass index, 20.1-24.8 kg/m²). Inclusion criteria included a healthy status confirmed by medical documentation (complete medical history, physical examination, chest radiography, serum laboratory evaluation, and electrocardiography). Other inclusion criteria included abstinence from all drug as well as alcoholic or caffeinated beverages for 2 weeks prior to study entry. Subjects were excluded from the study if they had a history or evidence of a renal, gastrointestinal, hepatic, or hematologic abnormality or any acute or chronic disease. This was done to ensure that the existing degree of variation would not be due to an influence of illness or other medications. Eligible subjects were informed of the aim and risks of the study by the clinical investigators and provided written informed consent prior to study initiation.

This study was performed in accordance with the current revision of the Declaration of Helsinki, ${ }^{6}$ Good Clinical Practice, ${ }^{7}$ and Good Laboratory Practice. ${ }^{8}$ The study and the informed consent form were approved prior to the start of the study by the First Hospital of Nanjing Medical University ethnics committee.

Subjects were admitted to the hospital at 9 pm the day before the study and fasted 8 hours before each drug administration. A computer-generated random number table was used to assign subjects in a 1:1 ratio to receive a single $8 \mathrm{mg}$ dose of the test or reference formulation of ondansetron. Subjects and investigators were blinded to sequence. As the $t_{1 / 2}$ of ondansetron oral soluble film is 4.6 hours, a 1 -week washout period followed administration of the initial formulation, after which the alternate formulation was administered.

\section{Chemicals and reagents}

Ondansetron (lot: RS1002100510, the reference standard; purity: 100.3\%) and lacosamide (lot: 20120316-2, the internal standard [IS]; purity: 99.51\%) were provided by Hangzhou Pharm \& Chem Co., Ltd. (Hangzhou, People's Republic of China). Highperformance liquid chromatography (HPLC) grade of methanol and methyl tert-butyl ether was purchased from Tedia Company (Fairfield, OH, USA). Other reagents were all of analytical grade and were purchased from Nanjing Chemical Reagent Co., Ltd. (Nanjing, People's Republic of China).

The test formulation ( $8 \mathrm{mg}$ ondansetron oral soluble film) was manufactured by Jiangsu Hengrui Pharmaceutical Co. Ltd. The reference formulation was the leading product in the international market (Zuplenz ${ }^{\circledR}$, Galena Biopharma, Inc.) and provided by Jiangsu Hengrui Pharmaceutical Co. Ltd.

\section{Blood sampling and assaying}

After the 8-hour overnight fast and before administration of the study drug, blood was drawn for baseline (time 0) measurements. A 20 G catheter (WeiGao Company, Shandong, People's Republic of China) was placed in a forearm vein, and a $5 \mathrm{~mL}$ blood sample was drawn into a vacuum tube with heparin sodium (Shanghai Biochemistry Co., Ltd., Shanghai, People's Republic of China) as an anticoagulant. Additional blood samples were drawn at 20 minutes, 40 minutes, 60 minutes, 80 minutes, 100 minutes, 120 minutes, 140 minutes, and 160 minutes and 3 hours, 4 hours, 6 hours, 8 hours, 10 hours, 12 hours, 14 hours, and 24 hours after dosing. Subjects were provided with a standard meal (60\% carbohydrate, $30 \%$ protein, and $10 \%$ fat; $~ 900 \mathrm{kcal}$ ) at 4 hours and 10 hours after studying drug administration in each treatment group. Plasma was immediately separated by nonrefrigerated centrifuge (Jiangsu Jintan Huanyu Instrument Company, Changzhou, People's Republic of China) at $1,072 \mathrm{~g}(r=0.03 \mathrm{~m})$ for 10 minutes and then stored at $-65^{\circ} \mathrm{C}$ until analyzed by Agilent 6460A Triple 
Quad LC-MS/MS systems with multiple reaction monitoring (Agilent Technologies, Santa Clara, CA, USA). After washout period and administration of the alternate formulation, blood samples were drawn and analyzed in the same way.

\section{Determination of ondansetron}

An HPLC system, Agilent 1200 series LC equipped with an autosampler, an online degasser, a binary pump, a thermostatted column compartment, and a UV detector connected with a Zorbax SB-C18 column $(3.5 \mu \mathrm{m}, 2.1 \mathrm{~mm} \times 100 \mathrm{~mm}$, Agilent Technologies), was used for chromatographic separation. MassLynx 4.0 analysis workstation (Waters Corporation) was used for system control, data acquisition, and quantification.

All the plasma was thawed at room temperature. In all, $100 \mu \mathrm{L}$ of thawed plasma was placed with $500 \mu \mathrm{L}$ of methyl tert-butyl ether (containing $10 \mu \mathrm{L}$ of $100 \mathrm{ng} / \mathrm{mL}$ IS lacosamide) into clean Eppendorf tubes, vortexed for $60 \mathrm{sec}$ onds, and centrifuged at $1,072 \mathrm{~g}$ for 5 minutes at $20^{\circ} \mathrm{C}$. Then $450 \mu \mathrm{L}$ of the supernatants were transferred to clean vials, evaporated to dryness at $37^{\circ} \mathrm{C}$ under nitrogen, and resolved with $200 \mu \mathrm{L}$ mobile phase.

For a complete separation of all the compounds, various concentrations of mobile phases were tested. The mobile phase of $0.1 \%$ methanoic acid aqueous solution/methanol (65:35, $\mathrm{vol} / \mathrm{vol}$ ) proved to show the best separation efficiency.
Then the column effluent was directly introduced into the MS detector Agilent Technologies 6460 Triple Quadrupole LC-MS/MS operated in a positive electrospray ionization (ESI) mode. Nitrogen was used as both the sheath gas and collision gas. The ESI source parameters were as follows: gas temperature $320^{\circ} \mathrm{C}$, gas flow $10 \mathrm{~L} / \mathrm{min}$, nebulizer gas pressure $45 \mathrm{psi}$, sheath gas temperature $300^{\circ} \mathrm{C}$, sheath gas flow $11 \mathrm{~L} /$ min, and capillary voltage 3,500 V. Fragmentor voltages were selected for ondansetron and IS ranging from $80 \mathrm{~V}$ to $140 \mathrm{~V}$ and $60 \mathrm{~V}$ to $120 \mathrm{~V}$, respectively. The parameters of collision energy were selected from ondansetron and are ranging from $16 \mathrm{eV}$ to $22 \mathrm{eV}$ and $0 \mathrm{eV}$ to $6 \mathrm{eV}$, respectively. The optimized conditions are as follows: fragmentor voltages of $120 \mathrm{~V}$ (ondansetron) and $60 \mathrm{~V}$ (IS), respectively. The parameters of collision energy are $22 \mathrm{eV}$ (ondansetron) and $2 \mathrm{eV}$ (IS). Samples were analyzed by LC-MS/MS in the multiple reaction monitoring mode to maximize sensitivity. Characteristic transitions (precursor ion $\rightarrow$ product ion) are $[\mathrm{M}+\mathrm{H}]^{+}$(ondansetron) $\mathrm{m} / \mathrm{z} 294.2 \rightarrow 170.2$ and $[\mathrm{M}+\mathrm{H}]^{+}$(IS) $m / z 251.2 \rightarrow 108.2$ (Figure 1).

\section{Method validation}

The validation of methods is characterized by sensitivity, specificity, linearity, recovery, accuracy, and interday and intraday precisions. The lower limit of quantification for this method was $0.2 \mathrm{ng} / \mathrm{mL}$, and the signal-to-noise ratio

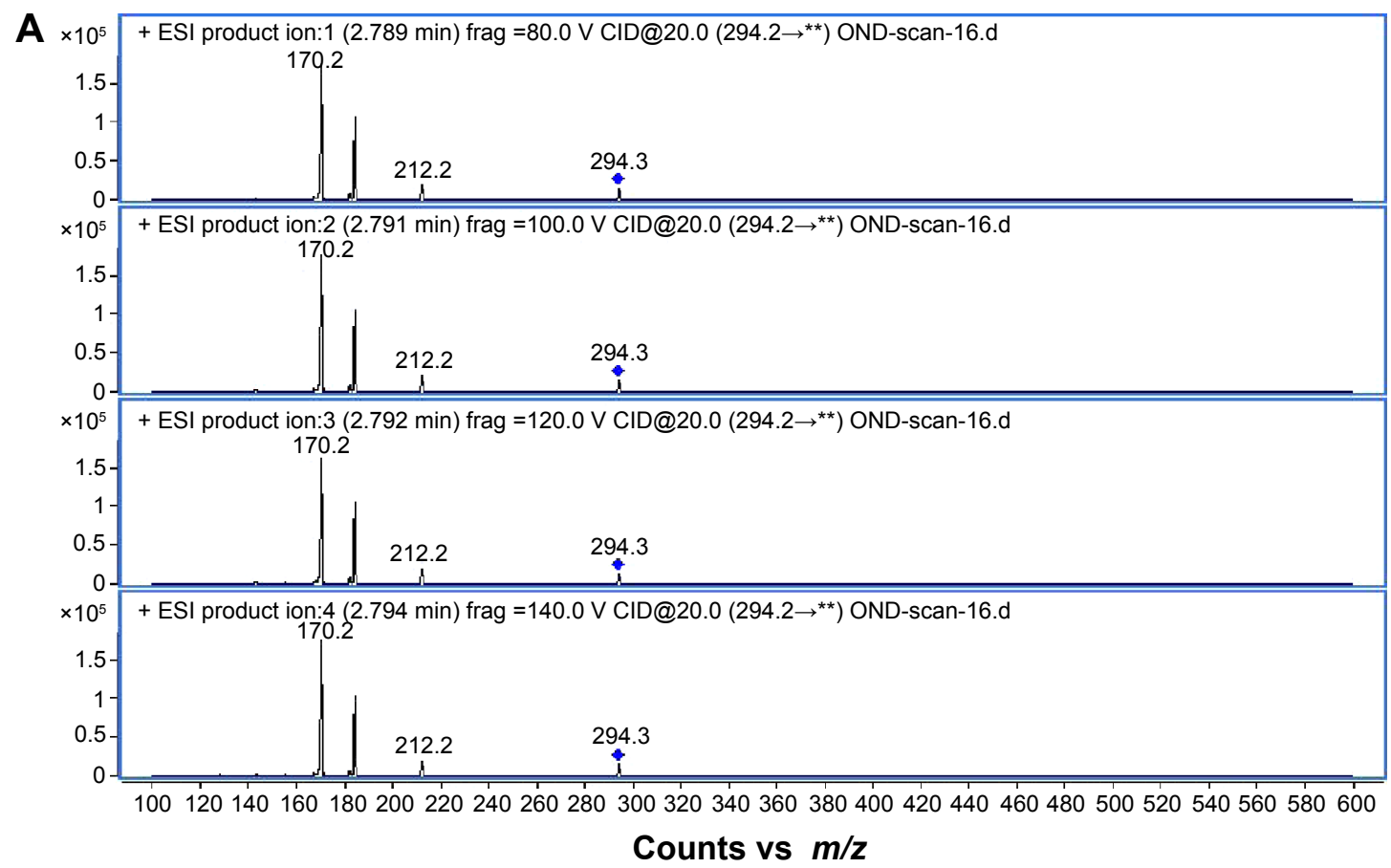

Figure I (Continued) 


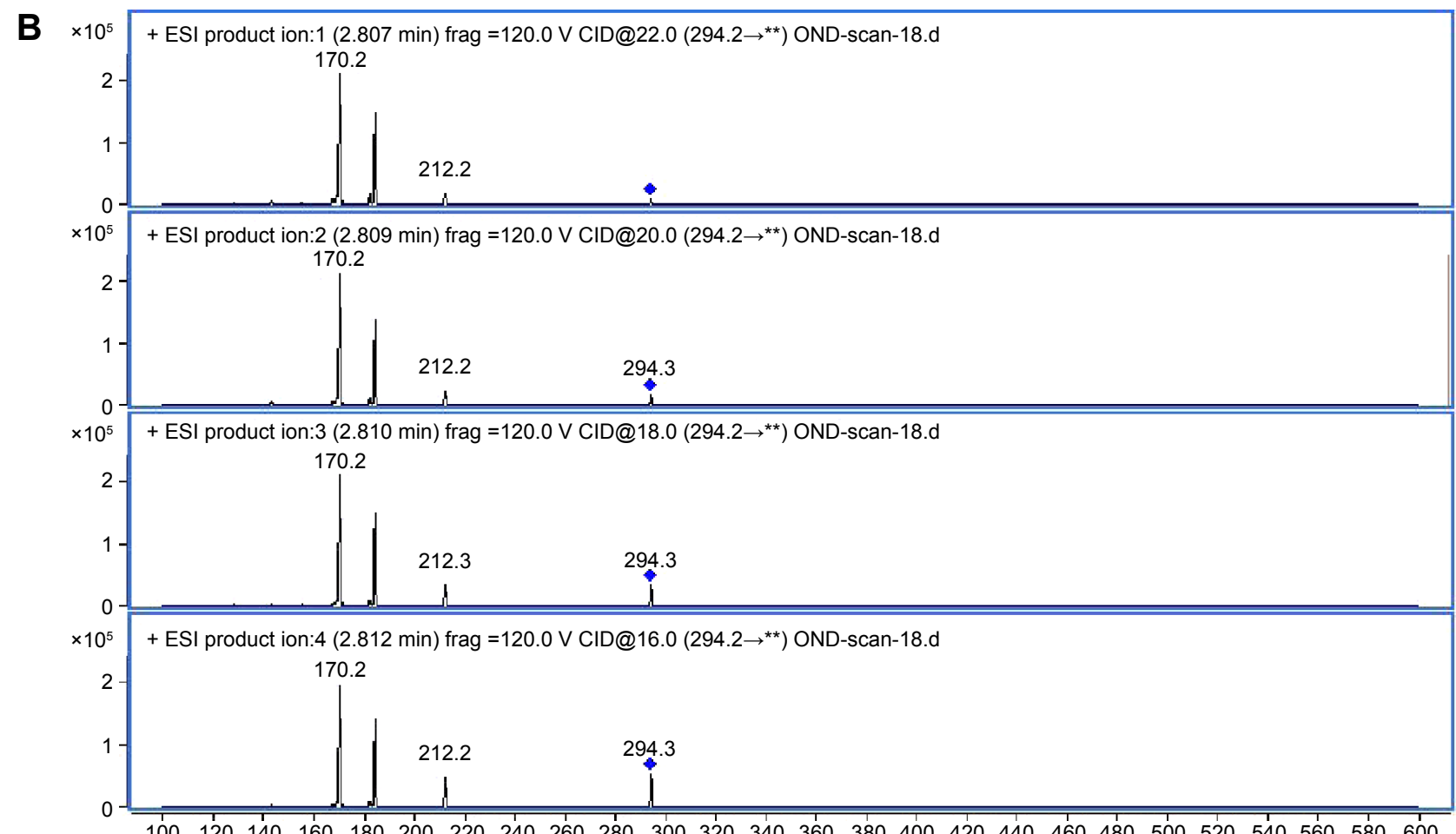

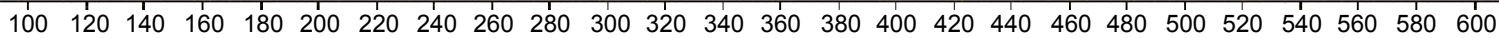

\section{Counts vs $\mathrm{m} / \mathrm{z}$}

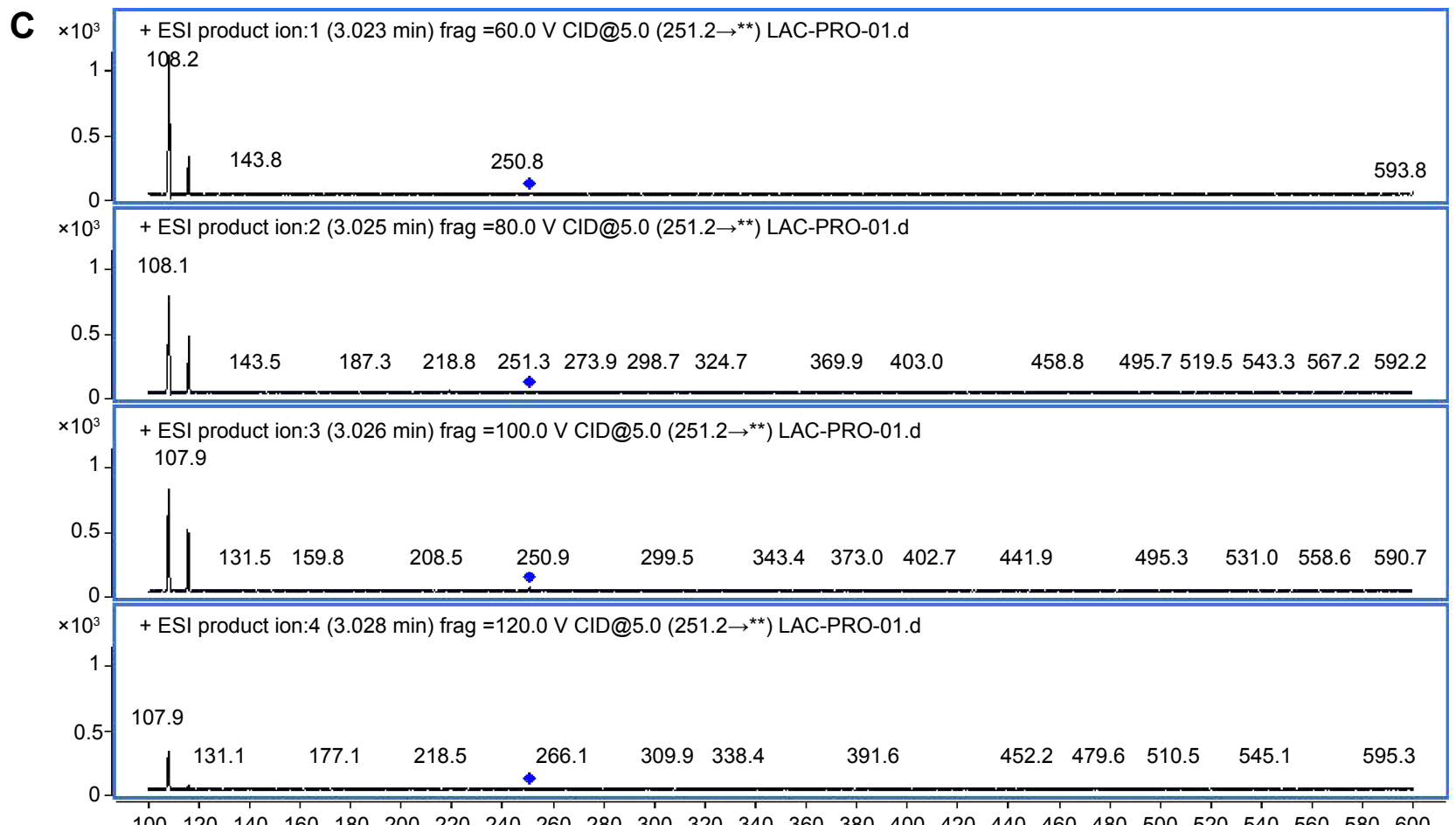

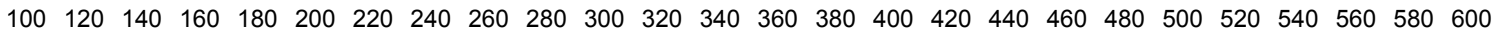

\section{Counts vs $m / z$}

Figure I (Continued) 


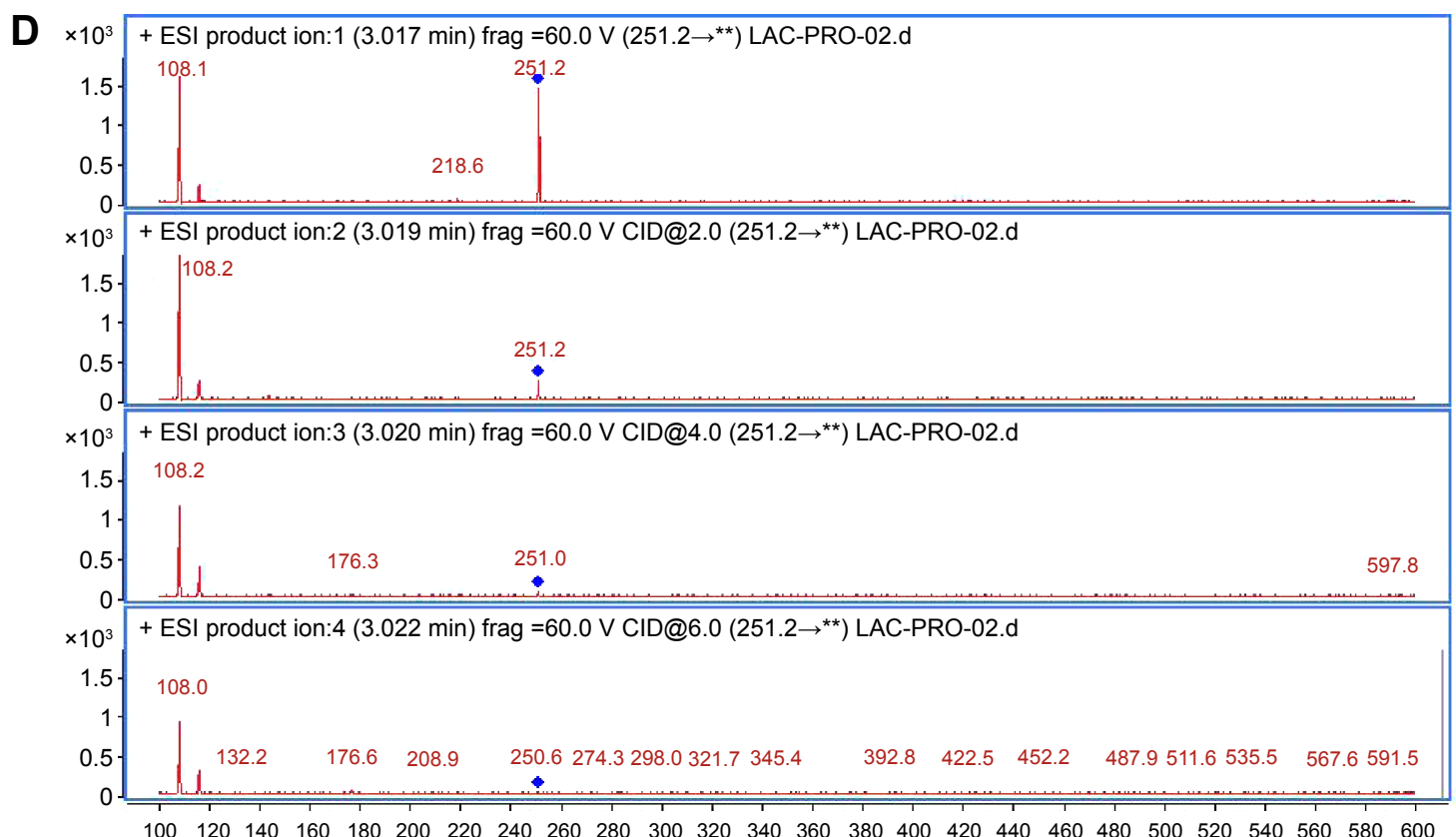

\section{Counts vs $m / z$}

Figure I The optimization chromatograms of (A) fragmentor voltages of ondansetron, (B) collision energy of ondansetron, (C) fragmentor voltages of lacosamide (IS), and (D) collision energy of lacosamide (IS). **refers to the general mark of the total ion chromatogram.

Abbreviations: IS, internal standard; ESI, electrospray ionization; min, minutes; $\mathrm{m} / \mathrm{z}$, mass-to-charge; CID, collision induced dissociation; LAC-PRO, internal standard lacosamide.

was $>5$. The samples were measured at three levels of $0.4 \mathrm{ng} / \mathrm{mL}, 4.0 \mathrm{ng} / \mathrm{mL}$, and $64.0 \mathrm{ng} / \mathrm{mL}$ of quality control (QC) concentrations in all cases, indicating the acceptable precision and accuracy of the method. No endogenous peaks interfering with quantification were observed throughout the validation process (Figure 2). The validation data, as presented in Table 1, were taken from our validation report. The values for intraday and interday precisions and accuracy (all $<7 \%$ in all cases) meet with the requirements of China Food and Drug Administration (CFDA) and US Food and Drug Administration (FDA) guidelines (Table 1).,10

\section{Matrix effects}

The matrix effects were evaluated by the QC samples of three different concentrations $(4.0 \mathrm{ng} / \mathrm{mL}, 40.0 \mathrm{ng} / \mathrm{mL}$, and $64.0 \mathrm{ng} / \mathrm{mL}$ ). In all, $100 \mu \mathrm{L}$ drug-free plasma or $100 \mu \mathrm{L}$ blank

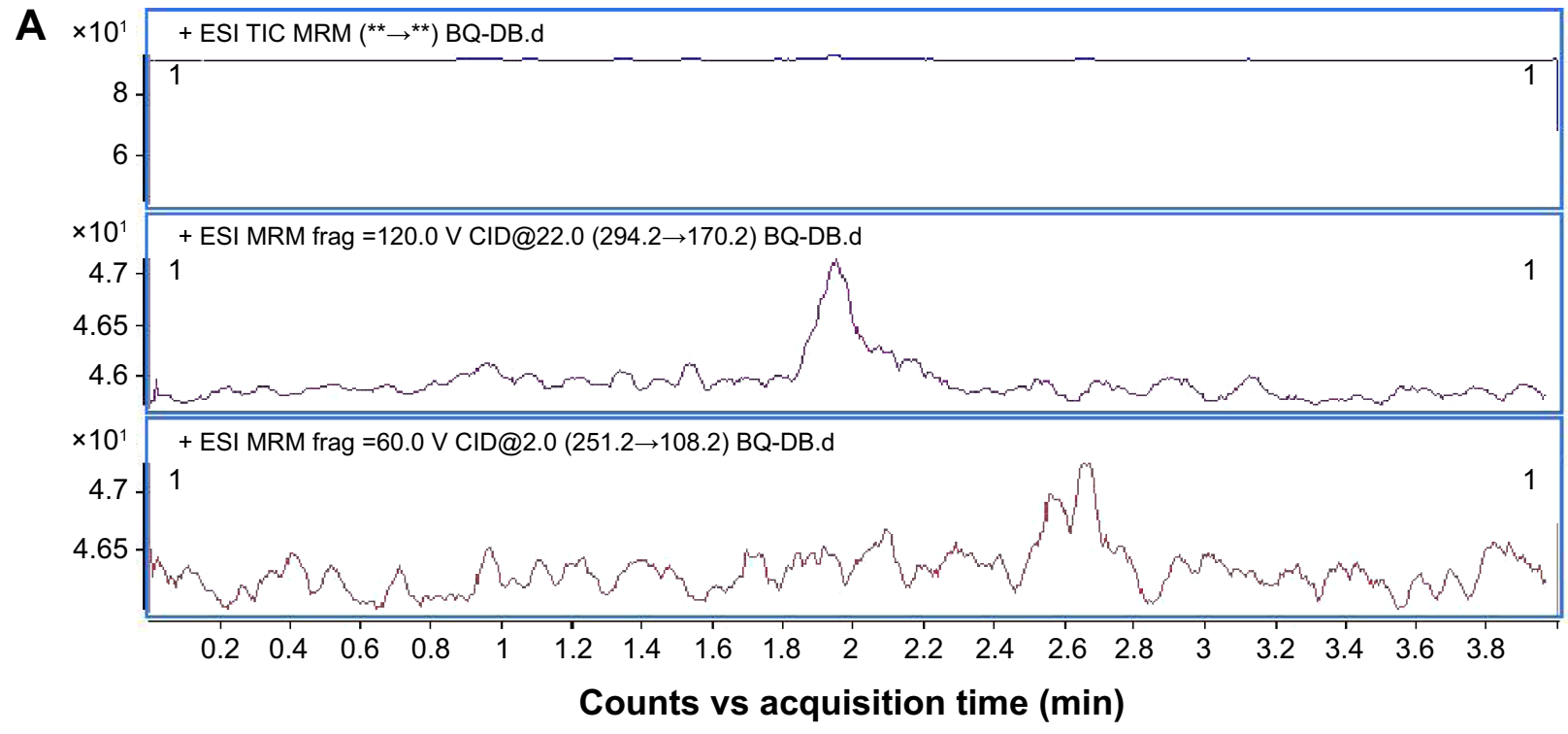

Figure 2 (Continued) 

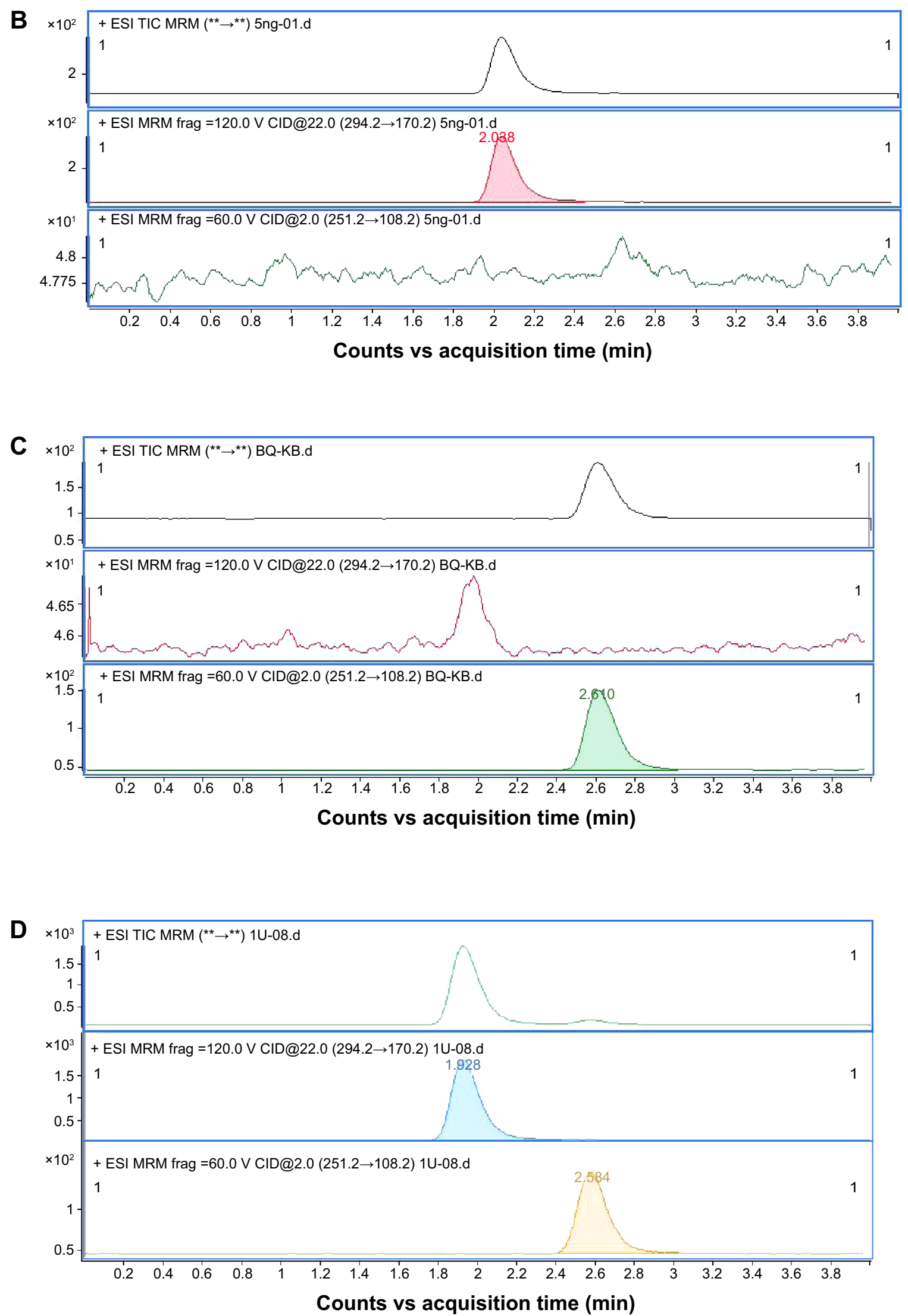

Figure 2 Chromatograms of (A) blank plasma, (B) blank plasma with ondansetron ( $2 \mathrm{ng} / \mathrm{mL})$, (C) blank plasma with ondansetron ( $10 \mathrm{ng} / \mathrm{mL})$, and (D) the volunteer $\mathrm{C}$ taking $8 \mathrm{mg}$ oral soluble ondansetron after $4 \mathrm{~h}$. **refers to the general mark of the total ion chromatogram.

Abbreviations: h, hours; ESI, electrospray ionization; MRM, multiple reaction monitoring; min, minutes; TIC, Total ion chromatogram; CID, collision induced dissociation. 
Table I Accuracy and interday and intraday precisions of ondansetron

\begin{tabular}{|c|c|c|c|c|c|c|}
\hline \multirow{2}{*}{$\begin{array}{l}\text { Spiked concentration } \\
(\mathrm{ng} / \mathrm{mL})\end{array}$} & \multicolumn{3}{|c|}{ Intraday precision } & \multicolumn{3}{|c|}{ Interday precision } \\
\hline & $\begin{array}{l}\text { Mean (SD) } \\
(n g / m L)\end{array}$ & $\begin{array}{l}\operatorname{RSD}^{b}(\%) \\
(n=5)\end{array}$ & $\begin{array}{l}\text { Accuracy }(\%) \\
(n=5)\end{array}$ & $\begin{array}{l}\text { Mean (SD) } \\
(\mathrm{ng} / \mathrm{mL})\end{array}$ & $\begin{array}{l}\operatorname{RSD}^{\mathrm{b}}(\%) \\
(\mathrm{n}=5)\end{array}$ & $\begin{array}{l}\text { Accuracy \% } \\
(n=5)\end{array}$ \\
\hline 0.4 & $0.370(0.022)$ & 5.94 & 93.31 & $0.400(0.025)$ & 6.22 & 103.79 \\
\hline 4.0 & $4.125(0.15 I)$ & 3.66 & 103.12 & $4.11(0.129)$ & 3.15 & 102.63 \\
\hline 64.0 & $66.283(2.172)$ & 3.28 & 103.57 & $64.85(2.028)$ & 3.40 & 101.32 \\
\hline
\end{tabular}

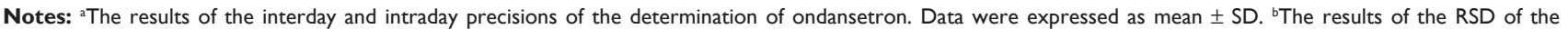
determination of ondansetron. Data were expressed as RSD (\%).

Abbreviations: SD, standard deviation; RSD, relative standard deviation.

matrix (distilled water) samples were prepared by the procedures of determination of ondansetron. Then we evaluated matrix effects by comparing the peak area of ondansetron and lacosamide (IS) of drug-free plasma $(\mathrm{n}=5)$ with them in blank matrix $(n=5)$. Mean (SD) of the ratios of ondansetron and lacosamide (IS) were 95.44 (3.24) and 101.22 (3.11), respectively, which suggested that there were no matrix effects that affect the determination of ondansetron.

\section{PK and statistical analysis}

Using a power analysis (expected value, $\geq 1-\beta=0.8$ ), it was determined that the power of the analysis of variance (ANOVA) was $>0.8$ at a $90 \%$ confidence interval (CI), according to the $\mathrm{FDA}^{11}$ guidelines on bioequivalence testing, indicating that ten subjects would be sufficient for the purposes of the study.

A noncompartmental PK method was employed to determine the PK properties of ondansetron. $C_{\max }$ and $T_{\max }$ were obtained directly from the plasma concentration-time curves of ondansetron. Other PK parameters $\left(\mathrm{AUC}_{0-\infty}\right.$, elimination rate constant $\left(k_{\mathrm{e}}\right)$, and $\left.t_{1 / 2}\right)$ were calculated on noncompartmental analysis using Drug and Statistics Software version 2.1 (University of Science and Technology, Hefei, People's Republic of China). $\mathrm{AUC}_{0-24}$ was calculated using the trapezoidal rule. ${ }^{12} \mathrm{AUC}_{0-\infty}$ was calculated as follows:

$$
\mathrm{AUC}_{0-\infty}=\mathrm{AUC}_{0-24}+C_{24} / k_{\mathrm{e}}
$$

where $C_{24}$ represented the last measurable concentration. $k_{\mathrm{e}}$ was determined from the slope of the natural logarithm (ln)-linear portion of the plasma concentration-time curve using least-squares regression analysis, and $t_{1 / 2}$ was estimated using the following equation:

$$
t_{1 / 2}=\frac{\ln 2}{k_{e}}
$$

The relative bioavailability $(F)$ of the test was calculated as follows:

$$
F=\frac{\mathrm{AUC}_{0-24 \text { (test) }}}{\mathrm{AUC}_{0-24 \text { (reference) }}} \times 100 \%
$$

To test the bioequivalence of the formulations, ANOVA for a two-way crossover design was performed on logtransformed $C_{\max }, \mathrm{AUC}_{0-24}$, and $\mathrm{AUC}_{0-\infty}$. The ratios of the log-transformed $C_{\max }, \mathrm{AUC}_{0-24}$, and $\mathrm{AUC}_{0-\infty}$ were obtained for both formulations, and ANOVA was performed using the $F$-score. The probability of exceeding the limits of acceptance $(80 \%-125 \%)$ was obtained using two-sided $t$-tests, as described by Schuirmann ${ }^{13}$ and the FDA. ${ }^{11}$ The $90 \%$ CIs of the geometric means of the individual test/reference $(T / R)$ ratios for $C_{\max }, \mathrm{AUC}_{0-24}$, and $\mathrm{AUC}_{0-\infty}$ were obtained.

\section{Results}

In all, ten male subjects (mean [range] age, 28.4 years [18-40 years]; weight, $62.4 \mathrm{~kg}$ [55-75 kg]; height, $172 \mathrm{~cm}$ [163-184 cm]) were enrolled in the study. Five subjects each received the test or reference formulations first changed after 1 -week period. All volunteers completed the study. The mean ondansetron concentration-time profiles after administration of the two formulations are shown in Figure 3.

The values of the PK parameters $\left(\mathrm{AUC}_{0-24}, \mathrm{AUC}_{0-\infty}\right.$, $C_{\max }, t_{1 / 2}$, and $\left.T_{\max }\right)$ and the geometric mean ratios $(90 \% \mathrm{CI})$ of $\mathrm{AUC}_{0-24}, \mathrm{AUC}_{0-\infty}$, and $C_{\max }$ of ondansetron are presented in detail in Table 2.

Out of three volunteers, two experienced abdominal pain after administration of the test and reference formulation and one experienced skin rash after administration of the reference formulation. All the symptoms resolved spontaneously within 1 hour. Physical examination revealed no abnormalities attributable to ondansetron administration. The studied biochemical, hematological, and electrocardiography (ECG) parameters revealed no abnormalities. The subjects were closely monitored after the symptoms resolved, and no other effects were reported. The adverse events (AEs) were considered by three independent investigators as mild. None of the volunteers withdrew from the study. No serious AEs were reported. At the 


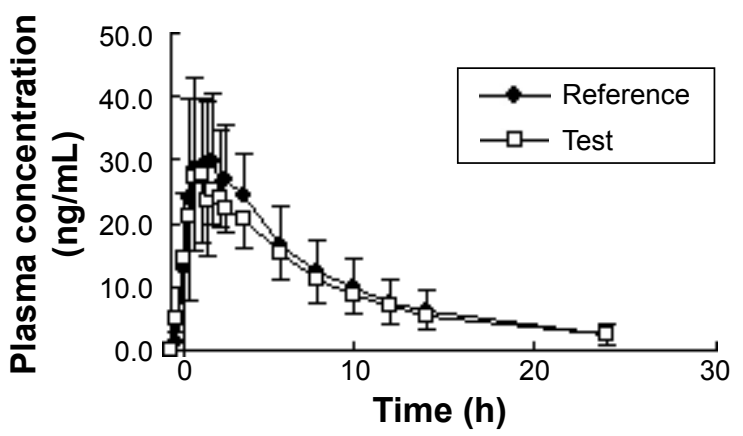

Figure 3 Mean (SD) concentration-time profiles after single-dose oral administration of the test and reference $8 \mathrm{mg}$ ondansetron oral soluble film formulation $(n=10$, lower limit of quantification $=0.2 \mathrm{ng} / \mathrm{mL}$ ).

Abbreviations: SD, standard deviation; h, hours.

end of the study, all vital signs were considered to be normal in all subjects on the basis of physical examination and results of blood chemistry analysis. There were no significant AEs encountered during this bioequivalence study.

\section{Discussion}

The aim of this study was to investigate the PK properties of two $8 \mathrm{mg}$ oral soluble film formulations of ondansetron in a healthy Chinese adult male population to obtain regulatory approval for the test formulation.

Previous studies reported many methods, such as radioimmunoassay, ${ }^{14}$ spectrophotometric, ${ }^{15}$ HPLC-UV, ${ }^{16}$ high-performance thin layer chromatography, ${ }^{17}$ and capillary electrophoresis, ${ }^{18}$ to determine the plasma concentrations of ondansetron. However, these methods have some drawbacks such as laborious sample preparation procedures, timeconsuming gradient elution, lower sensitivity, and comparatively longer runtime, which limited their application to large amounts of quantification in biological fluids. LC-MS/MS ${ }^{19,20}$ was recently the most commonly used method to determine the plasma, but it required expensive and time-consuming

Table 2 Pharmacokinetic parameters after a single-dose oral administration of a $8 \mathrm{mg}$ ondansetron soluble film formulation of the test and reference drug

\begin{tabular}{|c|c|c|}
\hline Parameter & Test $(\text { mean } \pm \text { SD) })^{a}$ & Reference (mean \pm SD) \\
\hline$C_{\max }, \mathrm{ng} / \mathrm{mL}$ & $34.48 \pm 9.18$ & $36.90 \pm 9.38$ \\
\hline$T_{\max }, \mathrm{h}$ & $1.6 \pm 0.9$ & $1.7 \pm 1.0$ \\
\hline$t_{1 / 2}, \mathrm{~h}$ & $6.93 \pm 1.56$ & $6.39 \pm 1.64$ \\
\hline MRT, h & $9.69 \pm 2.31$ & $9.04 \pm 2.50$ \\
\hline $\mathrm{AUC}_{0-24}, \mathrm{ng} / \mathrm{mL} / \mathrm{h}$ & $234.35 \pm 57.76$ & $253.86 \pm 92.21$ \\
\hline $\mathrm{AUC}_{0-\infty}, \mathrm{ng} / \mathrm{mL} / \mathrm{h}$ & $256.55 \pm 72.27$ & $278.54 \pm 111.74$ \\
\hline$F, \%$ & $96.5 \pm 23.7$ & - \\
\hline
\end{tabular}

Note: a ${ }^{D}$ ata are expressed as mean $\pm S D$.

Abbreviations: SD, standard deviation; $C_{\max }$, peak plasma concentration of the drug; $T_{\text {max }}$ time needed to achieve $C_{\text {max }} ;$ h, hours; $t_{12}$, elimination half-life; MRT, mean residence time; AUC, area under the plasma concentration-time curve; $\mathrm{AUC}_{0-24}$, AUC from time $0 \mathrm{~h}$ to $24 \mathrm{~h}$. solid phase extraction columns, which are not fit for using in developing countries. As ondansetron is a medium polar compound, the determination of biological fluids always suffered with residues in the chromatography systems, especially for the concentration of low limitation of quantification.

So it is necessary to develop a rapid, accurate, precise, and sensitive method to overcome the drawbacks of reported methods. We created and validated a LC-MS/MS method for the determination and the quantification of ondansetron in human plasma. Compared to previous studies, gradient elution was always used in the determination of ondansetron for better results in chromatographic separation. We used isocratic elution to save analytical times and the mobile phase with good sensitivity. According to the results of specificity, the assay is suitable for the PK research of ondansetron in humans.

Quimby et al studied the PK parameters of ondansetron in healthy cats with approximately a single $0.4 \mathrm{mg} / \mathrm{kg}$ dose of oral, subcutaneous, and intravenous formulation. ${ }^{21}$ The $t_{1 / 2}$ of ondansetron was $1.84 \pm 0.58$ hours (intravenous), $1.18 \pm 0.27$ hours (oral), and $3.17 \pm 0.53$ hours (subcutaneous), suggesting that subcutaneous administration of ondansetron to healthy cats is a more prolonged exposure than oral and intravenous administration. Dychter et al studied the PK properties with a single $8 \mathrm{mg}$ dose of ondansetron. The PK data of ondansetron were $\mathrm{AUC}_{0-\infty} 287.19 \mathrm{ng} / \mathrm{mL} / \mathrm{h}$ and $C_{\max } 33.5$ hours. ${ }^{2}$ Dadey reported bioequivalence study in healthy Indian populations. ${ }^{4}$ The results of a single $8 \mathrm{mg}$ dose ondansetron were $\mathrm{AUC}_{0-\infty} 293.73 \mathrm{ng} / \mathrm{mL} / \mathrm{h}$ and $C_{\max }$ 39.05 hours, which had similar PK properties with the orally disintegrating formulations in their study.

The mean (SD) data for the test and reference drug ondansetron in our study were $t_{1 / 2} 6.93$ hours ( 1.56 hours) and 6.39 hours (1.64 hours), $C_{\max } 34.48 \mathrm{ng} / \mathrm{mL}(9.18 \mathrm{ng} / \mathrm{mL})$ and $36.90 \mathrm{ng} / \mathrm{mL}$ $(9.38 \mathrm{ng} / \mathrm{mL})$, and $\mathrm{AUC}_{0-\infty} 256.55 \mathrm{ng} / \mathrm{mL} / \mathrm{h}(72.27 \mathrm{ng} / \mathrm{mL} / \mathrm{h})$ and $278.54 \mathrm{ng} / \mathrm{mL} / \mathrm{h}(111.74 \mathrm{ng} / \mathrm{mL} / \mathrm{h})$, respectively. These values were similar to the results in the previous literature. ${ }^{4}$ The $90 \%$ CIs of the $T / R \mathrm{AUC}_{0-24}$ and $C_{\max }$ ratios of ondansetron were $91.38 \%-108.60 \%$ and $84.71 \%-103.28 \%$, respectively. The differences between the test and reference products for $C_{\max }$ and AUC values were not found to be statistically significant $(P<0.05)$, which can be assumed to be bioequivalent according to FDA and CFDA guidelines. ${ }^{9,10}$ There were no significant AEs encountered during this study, which suggested that all the two formulations are well tolerated.

\section{Conclusion}

Based on the PK results of this study, it was concluded that the two formulations of the $8 \mathrm{mg}$ ondansetron oral soluble formulations were bioequivalent. 


\section{Study limitation}

This study was a single-dose, open-label design in a small group of young healthy male volunteers; therefore, the study results cannot be extrapolated to female, older population or to patients. Additionally, although sex differences were reported on the PK parameters of ondansetron, they are not discussed in this study as our study aims to estimate the bioequivalence of the test and reference formulations.

\section{Acknowledgment}

The authors would like to acknowledge Jiangsu Hengrui Pharmaceutical Co. Ltd. for providing the test formulation of ondansetron and the reference standards used in this research.

\section{Disclosure}

The authors have indicated that they have no conflicts of interest in this work.

\section{References}

1. Mujtaba A, Kohli K, Ali J, Baboota S. Development of HPTLC method for the estimation of ondansetron hydrochloride in bulk drug and sublingual tablets. Drug Test Anal. 2013;5:122-125.

2. Dychter SS, Harrigan R, Bahn JD, et al. Tolerability and pharmacokinetic properties of ondansetron administered subcutaneously with recombinant human hyaluronidase in minipigs and healthy volunteers. Clin Ther. 2014;36(2):211-224.

3. Gabriel J. Subcutaneous fluid administration and the hydration of older people. Br J Nurs. 2014;23(14):S12-S14.

4. Dadey E. Bioequivalence of ondansetron oral soluble film $8 \mathrm{mg}$ (ZUPLENZ) and ondansetron orally disintegrating tablets $8 \mathrm{mg}$ (ZOFRAN) in healthy adults. Am J Ther. 2015;22(2):90-97.

5. Choudhary DR, Patel VA, Chhalotiya UK, Patel HV, Kundawala AJ. Comparative pharmacokinetic studies of fast dissolving film and oral solution of ondansetron in rats. Curr Drug Deliv. 2013;10(6):696-700.

6. World Medical Association. Declaration of Helsinki. Ethical principles for Medical Research Involving Human Subjects. Adopted by the 18th WMA General Assembly, Helsinki, Finland, June 1964 and Amended by the 64th WMA General Assembly, Fortaleza, Brazil, October, 2013; 2015. Available from: http://www.wma.net/en/30publications/10policies b3/index.html

7. International Conference on Harmonisation Expert Working Group. ICH Harmonised Tripartite Guideline: Guideline for Good Clinical Practice E6 (R1). Geneva, Switzerland: International Conference on Harmonisation; 1996.
8. Organization for Economic Co-operation and Development. OECD Series on Principles of Good Laboratory Practice and Compliance Monitoring Number 1: OECD Principles on Good Laboratory Practice. Paris, France: Organization for Economic Co-operation and Development; 1997.

9. China Food and Drug Administration (CFDA), Center for Drug Evaluation. Guideline for Bioavailability and Bioequivalence Studies of Generic Drug Products [in Chinese]. Available from: http://www. sda.gov.cn/gsz05106/08.pdf. Accessed July 31, 2015.

10. Center for Drug Evaluation and Research, US Food and Drug Administration. Guidance for Industry. Human Drugs In Vivo Bioequivalence Compliance Program. Available from: http://www.fda.gov/downloads/ ICECI/EnforcementActions/BioresearchMonitoring/UCM133760.pdf. Accessed July 31, 2015.

11. Center for Drug Evaluation and Research, US Food and Drug Administration. Guidance for Industry: Human Drugs In Vivo Bioequivalence Compliance Program 7348.001. Available from: http://www.fda.gov/ora/ complianceref/bimo/7348_001/default.htm. Accessed July 31, 2015.

12. Center for Drug Evaluation and Research, US Food and Drug Administration, Guidance for Industry. Bioanalytical Method Validation. Available from: http://www.fda.gov/cder/guidance/4252fnl.htm

13. Schuirmann DJ. A comparison of the two one-sided tests procedure and the power approach for assessing the equivalence of average bioavailability. J Pharmacokinet Biopharm. 1987;15:657-680.

14. Wring SA, Rooney RM, Goddard CP, Waterhouse I, Jenner WN. A sensitive radio-immunoassay, combined with solid-phase extraction, for the sub-nanogram per $\mathrm{ml}$ determination of ondansetron in human plasma. J Pharm Biomed Anal. 1994;12(3):361-371.

15. Bourdon F, Lecoeur M, Odou P, Vaccher C, Foulon C. Complementarity of UV-PLS and HPLC for the simultaneous evaluation of antiemetic drugs. Talanta. 2014;120:274-282.

16. Chandrasekar D, Ramakrishna S, Diwan PV. A rapid, sensitive and validated method for the determination of ondansetron in human plasma by reversed-phase high-pressure liquid chromatography. Arzneimittelforschung. 2004;54(10):655-659.

17. Raval PB, Puranik M, Wadher SJ, Yeole PG. A validated HPTLC method for determination of ondansetron in combination with omeprazole or rabeprazole in solid dosage form. Indian J Pharm Sci. 2008;70(3):386-390.

18. Li L, Xu L, Huang J, You T. On-line focusing of 5-hydroxy-tryptamine type 3 receptor antagonists via the combination of field-enhanced sample injection and dynamic $\mathrm{pH}$ junction in capillary electrophoresis with amperometric detection. J Chromatogr A. 2014;1331:117-122.

19. Dotsikas Y, Kousoulos C, Tsatsou G, Loukas YL. Development and validation of a rapid 96-well format based liquid-liquid extraction and liquid chromatography-tandem mass spectrometry analysis method for ondansetron in human plasma. J Chromatogr B Analyt Technol Biomed Life Sci. 2006;836(1-2):79-82.

20. Xu X, Bartlett MG, Stewart JT. Determination of ondansetron and its hydroxy metabolites in human serum using solid-phase extraction and liquid chromatography/positive ion electrospray tandem mass spectrometry. J Mass Spectrom. 2000;35(11):1329-1334.

21. Quimby JM, Lake RC, Hansen RJ, Lunghofer PJ, Gustafson DL. Oral, subcutaneous, and intravenous pharmacokinetics of ondansetron in healthy cats. J Vet Pharmacol Ther. 2014;37(4):348-353.

\section{Publish your work in this journal}

Drug Design, Development and Therapy is an international, peerreviewed open-access journal that spans the spectrum of drug design and development through to clinical applications. Clinical outcomes, patient safety, and programs for the development and effective, safe, and sustained use of medicines are a feature of the journal, which

\section{Dovepress}

has also been accepted for indexing on PubMed Central. The manuscript management system is completely online and includes a very quick and fair peer-review system, which is all easy to use. Visit http://www.dovepress.com/testimonials.php to read real quotes from published authors. 